\title{
Insurance Industry During COVID-19 Pandemic: A Case of ASKI MBA Insurance Program
}

\author{
Lilia G. Salvador ${ }^{1}$, Rhenalyn D. Salvador ${ }^{2}$, Ronalyn A. Villariaza ${ }^{3}$, Maurice Camille B. \\ Rondon $^{4}$, Frederick G. Tangunan ${ }^{5}$, Felipe E. Balaria ${ }^{6}$
}

\author{
${ }^{1}$ ASKI Mutual Benefit Association, Inc. - Cabanatuan City, Nueva Ecija, Philippines \\ ${ }^{2}$ Landbank of the Philippines - Cabanatuan City, Nueva Ecija, Philippines \\ ${ }^{3}$ Nueva Ecija University of Science and Technology - San Isidro, Nueva Ecija, Philippines \\ ${ }^{4}$ MBA, Graduate School - NEUST, Cabanatuan City, Philippines \\ ${ }^{5}$ BICOS National High School-Rizal, Nueva Ecija, Philippines \\ ${ }^{6}$ Program Chair, MBA-NEUST, Cabanatuan City, Philippines
}

Received: 20 May 2021; Received in revised form: 12 Jun 2021; Accepted: 22 Jun 2021; Available online: 06 Jul 2021

\begin{abstract}
This study described the effects of the COVID-19 pandemic on the ASKI MBA Insurance program and showed how the company adapted and managed the challenges the pandemic brought. Using a purposive sampling design, the researchers carefully conducted surveys and interviews on 10 (ten) ASKI $M B A$ employees coming from various departments. Collected data were analyzed using the descriptive method. Results of the study revealed that ASKI MBA decreased sales from 11.078 million in the year 2019 to 2.128 million in 2020 resulting in a decrease in income by the end of 2020 of almost 8.95 million. The findings also gave us an idea of how many policies were produced amid the pandemic, 10,921. This amounts to $21.22 \%$ of the total 51,455 policies in force during the pandemic. Given the total number, information also displayed that there were 301 COVID-19 insurance claims. This number represents $0.58 \%$ of the total insurance volume. Because of the restrictions in the different areas of operations, ASKI $M B A$ started to transition and adapt to digitization. This involves the online payment of insurance premiums, assessment of claims documents, and delivery of benefits. ASKI MBA will most certainly need to sustain its operational resilience and solvency management plans for some time. This should go hand in hand while fulfilling potentially complicated and evolving clients' expectations while providing critical services to policyholders.
\end{abstract}

Keywords-Insurance, challenges, claims, clients, coping plans, financial income, pandemic.

\section{INTRODUCTION}

People's financial stability is protected by the insurance industry through effective and efficient long-term savings mobilization. The COVID-19 pandemic, as well as the economic downturn, left a huge impact on life insurance and annuity providers. The global crisis brought by the pandemic challenged insurance companies in maintaining the stability and success of their businesses, both shortterm and long-term [1].

"Financial institutions play a significant role in the socioeconomic growth and development of a nation. Insurance companies, in particular, facilitate a nation's innumerable economic transactions through efficient and effective savings mobilization, risk transfer and indemnification, and financial intermediation processes" [2] [3]. "By mobilizing long-term savings, these companies provide financial security to a nation's citizens" [2].

The Philippine insurance market is currently developing and evolving. With the advent of banks, mutual funds, and financial institutions offering a diverse variety of financial security products, the sector is expected to grow even more [4].

ASKI Mutual Benefit Association, Inc., is a business unit belonging to the ASKI Group of Companies. In 1995, 
ASKI started giving financial assistance to its clients for their hospitalization and medical expenses. ASKI also gave donations to the bereaved family of the client in times of death. On June 21, 2006, AlalaysaKaunlaran Mutual Benefit Association (ASKI MBA) was born. On October 5, 2006, ASKI MBA was issued a license to operate by the Insurance Commission (IC). December 2006, ASKI MBA pilot-tested its program in Urdaneta Branch. And finally, in January 2007, operations were officially started [5].

According to "The Philippine Daily Inquirer, the latest Insurance Commission (IC) data showed that the insurance industry's bottom line declined 9.85 percent year-on-year to P28.62 billion during the first nine months of 2020 from P31.74 billion a year ago" [6][7]. This data showed how COVID-19 impacted the insurance industry. Given the uncertainty that exists in these unprecedented times, insurance companies were challenged to maintain business stability and success [8] [9]. This study aimed to describe the effects of the COVID-19 pandemic on the ASKI MBA Insurance program and the challenges faced and its response and coping plans will be discussed in this study. Specifically, it described the demographic profile of ASKI MBA as to their monthly incomebefore and during the pandemic. Likewise, it described the insurance claims granted relating to COVID-19 and the client's insurance- buying behavior before and during COVID-19. Also, it explored the challenges of ASKI MBA during the pandemic and the coping plans and strategies of ASKI MBA during the pandemic

\section{METHODOLOGY}

The researchers confined their study with ASKI MBA located at 105 Maharlika Highway, Cabanatuan City. Theyhave purposively chosen 10 respondents [10], [11]. This method is typically used in basic qualitative research [12] to identify and select the information-rich cases for the most proper utilization of available resources. Two (2) from the Management Department, one (1) from the Finance Department, and seven (7) from the Operations Department. Questions for this category investigated the financial losses to the company and current relations it has with clients. A survey questionnaire wasprepared and used in data collection. Follow-up questions were asked to clarify the responses of the respondents. The objectives of the research, confidentiality of the organization's information, and other ethical considerations stated in the survey protocols were explained to the respondents before data collection.

\section{RESULTS AND DISCUSSIONS}

\section{Demographic Profile of ASKI MBA}

\section{a. Monthly Income}

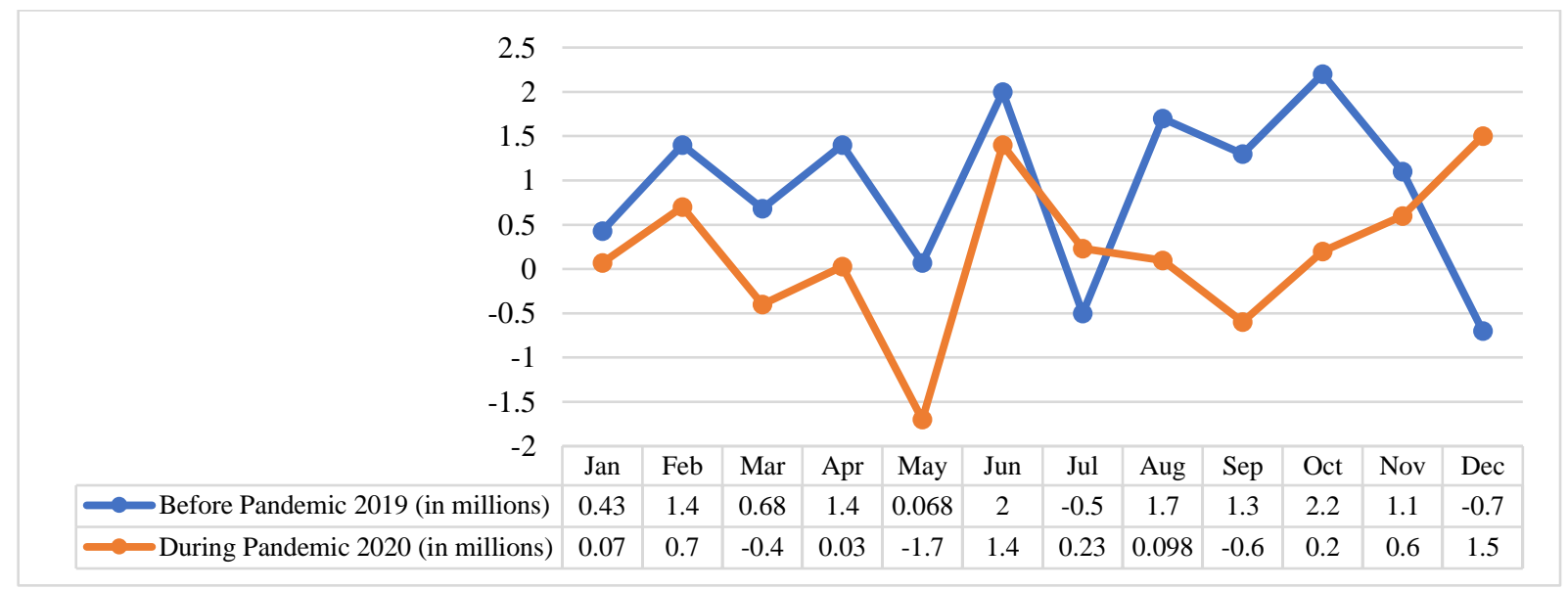

Fig.1: Monthly Income

The graph shows the monthly income of ASKI MBA before and after the pandemic. The blue line represents the monthly income of ASKI MBA for the year before the pandemic while the red represents the year during a pandemic. As shown in the graph, there is a decrease in the monthly income of ASKI MBA when the pandemic struck.
The income of ASKI MBA declined from 11.078 million in 2019 to 2.128 million in 2020 resulting in a decrease in income amounting to 8.95 million by the end of 2020 . The trend showed that monthly income in the first half of both years is quite similar; the monthly income in 2020 is lower 
than in 2019. Whereas the second half monthly income of

both years shows different results.

\section{Insurance Claims relating to COVID-19}

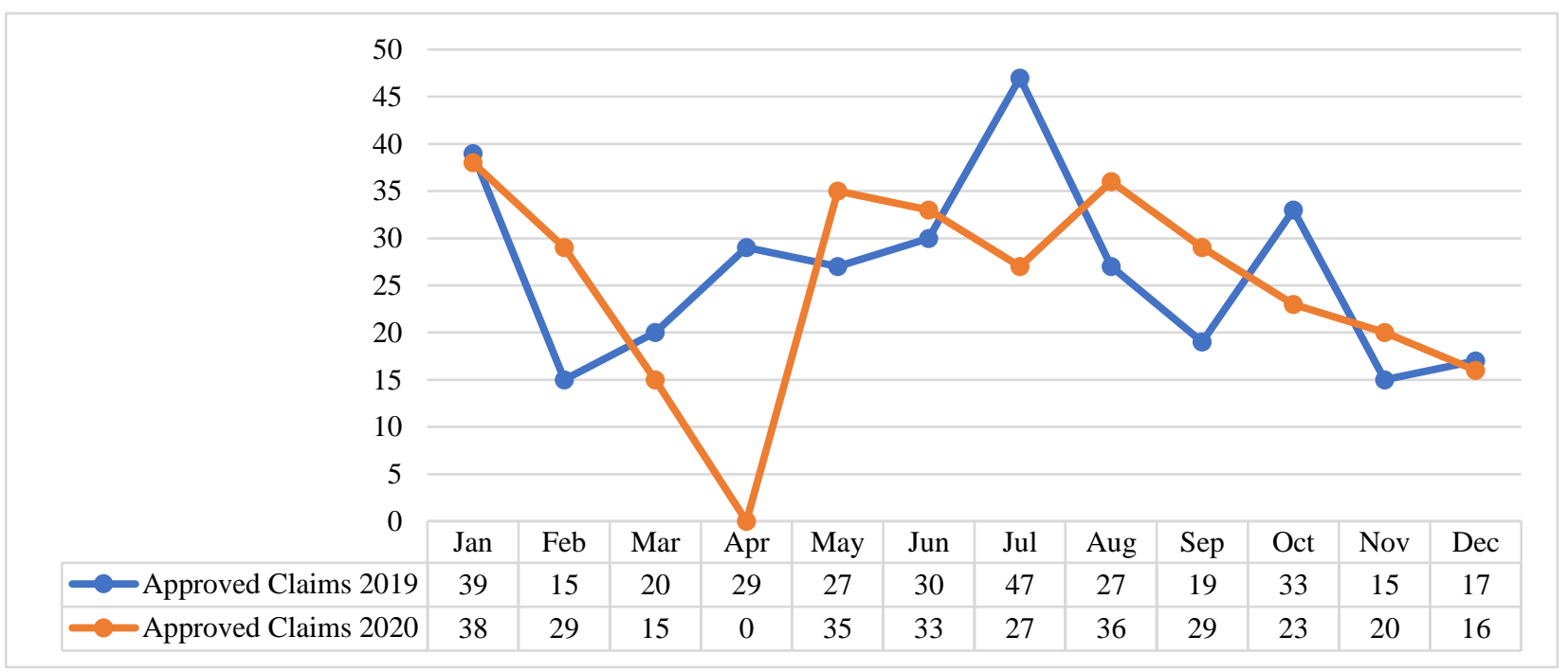

Fig.2: Number of Approved Claims

The blue line shows the number of approved claims before the pandemic while the red line shows the approved claims during the pandemic. While the total number of approved claims of 2020 is not far from the total approved claims of 2019, in April 2020 ASKI MBA recorded zero (0) approved claims that caused a tremendous plunge on the graph. As shown in the graph, there is no pattern in both years as to what month has the maximum and the minimum number of insurance claims.

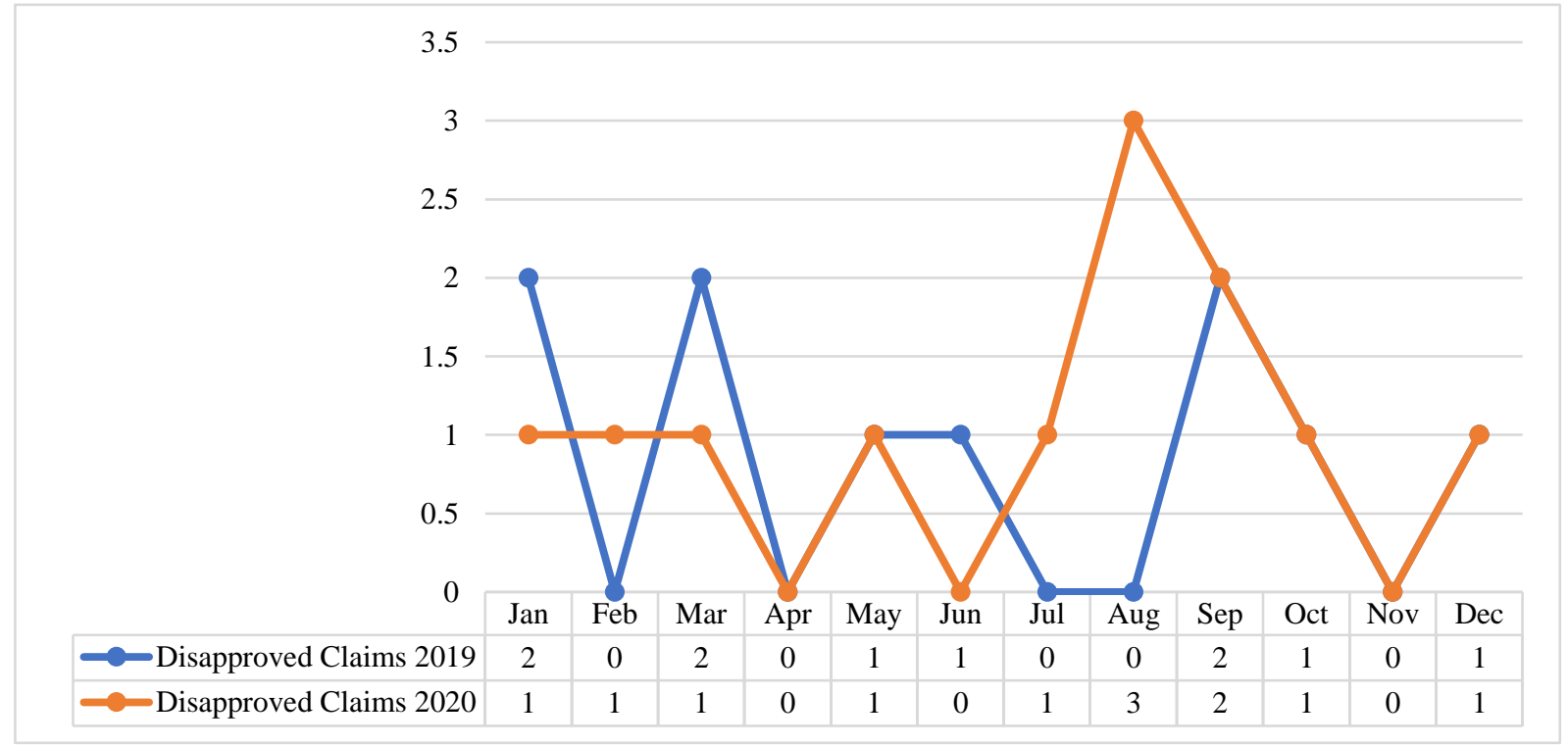

Fig.3: Number of Disapproved Claims

The blue line shows the number of disapproved claims before the pandemic (2019) while the red line shows the disapproved claims during the pandemic (2020). As shown in the graph, both line graphs present zero (0) disapproved claims in various months. The highest number of disapproved claims was recorded in August 2020. Disapproved claims in both years have the same trend in the last quarter of the year.

\section{Client's insurance-buying behavior before and during COVID-19}

This article can be downloaded from here: www.ijaems.com 


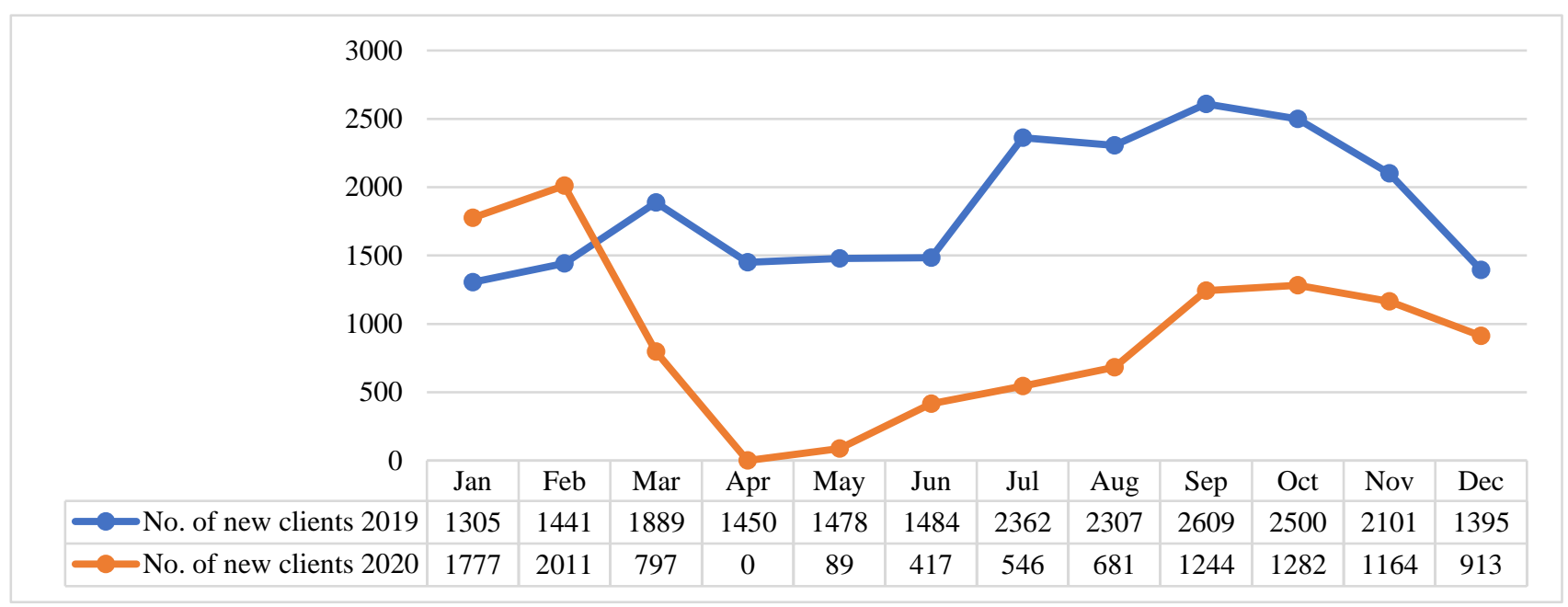

Fig.4: Number of New Clients Insured

Figure 4 shows the new clients' buying an insurance policy in the years 2019 and 2020. In 2019, before the spread of the COVID-19, ASKI MBA recorded the highest number of new clients availing of insurance policy on the month of September and lowest on the month of January. The totals are 2,609 and 1,305 new clients respectively. However, in 2020, when the COVID-19 spread throughout the country, a drop in the number of new clients availing insurance policies was recorded. In April 2020, ASKI MBA recorded zero (0) new clients. This caused a tremendous plunge on the graph.

\section{Challenges of ASKI MBA during the pandemic}

\section{a. Operational}

The majority of insurance firms have traditionally depended on face-to-face sales and service, as well as operating in physical locations hence the difficulty in dealing with complicated and high-value claims when reviewing physical evidence and receiving expert findings in person. An example of this is the Total Permanent Disability Claims. This claim requires a physical visit and a doctor's endorsement. Collection of premium is also a challenge for ASKI MBA since the community restrictions were imposed.

\section{b. Economic shock to customers}

A drop in the number of new clients is an evident challenge for the ASKI MBA. COVID-19's enormous influence on economic activity and employment levels has resulted in a large reduction in consumer purchasing power in a short period. Clients are facing financial difficulties as a result of job losses or reduced income. Based on the experience of the respondents, clients are unable to pay due to said reasons. Potential clients are declining to apply for insurance as it is not their priority especially in this time of the pandemic.

\section{c. Financial Performance and Stability}

The pandemic has a significant impact on ASKI MBA's financial situation, notably on the amount of premium and contribution received by the organization, which is its main source of income. Due mainly to the implementation of a moratorium on collections and the difficulties in reaching the clients because of lockdown to several aspects of the business the quantity of premiums and contributions received from the members has suddenly decreased.

\section{Coping and strategy plans of ASKI MBA during the pandemic}

\section{a. Operational}

With the restrictions, ASKI MBA is transitioning and adapting the digitization of customer interactions such as payment collections, benefit claims assessment, and distribution. Acquiring updated infrastructure (computers and servers) for MIS is one of their coping strategies for the efficient flow of communication within the organization. Submission of application and claim documents can be made online.

\section{b. Economic shock to customers}

To attract new clients, ASKI MBA engages social media in promoting its products and services. Strengthening the recruitment process of new clients is also one of the strategies of the organization through encouraging their employees through incentives to recruit new clients. In addition, attracting new clients by developing a software program to accommodate no hassle and efficient online enrolment 


\section{c. Financial Performance and Stability}

For a higher return on the investment portfolio, ASKI MBA began to boost its allocation to long-term investments. Also, it considered the need to conduct analysis and monitoring of portfolios and sensitivity to premium income as their strategy in recovering its financial performance and stability. In addition, ASKI MBA management came up with a plan to develop an online payment scheme, Barya Card. Barya Card is an application made by the ASKI management to make the collection of payments and giving the benefit claims of the clients easier.

\section{CONCLUSIONS AND RECOMMENDATIONS}

ASKI MBA decreased sales from 11.078 million in the year 2019 to 2.128 million in 2020 resulting in a decrease in income by the end of 2020 of almost 8.95 million. The findings also gave us an idea of how many policies were produced amid the pandemic, 10,921. This amounts to $21.22 \%$ of the total 51,455 policies in force during the pandemic. Given the total number, we were also informed that there were 301 COVID-19 insurance claims. This number represents $0.58 \%$ of the total insurance volume. Because of the restrictions in the different areas of operations, ASKI MBA started to transition and adapt to digitization. This involves the online payment of insurance premiums, assessment of claims documents, and delivery of benefits. ASKI MBA will most certainly need to sustain its operational resilience and solvency management plans for some time. This should go hand in hand while fulfilling potentially complicated and evolving clients' expectations while providing critical services to policyholders. The authors recommend to future researchers to focus on the following as a follow-up study: 1. The analysis of other insurance products during a pandemic; 2 . Other factors that caused the decrease of income of ASKI MBA not related to the pandemic; and 3. The application of other theories such as SWOT and Value Chain Analysis [13] to be used to analyze the general features and operations of certain insurance businesses.

\section{REFERENCES}

[1] Clark, M. \&, Nuttycombe, W. (2020) COVID-19 impact to life insurance and annuity companies. Deloitte.com., https://www2.deloitte.com/us/en/pages/financialservices/articles/covid-19-impact-to-life-insurance-andannuity-companies.html

[2] Mishkin, F. S. (2010). The economics of money, banking \& financial markets. [9th Edition]. United States: Addison Wesley.
[3] Salvatore, D. (2013). International Economics. [11th Edition]. United States: Fordham University.

[4] Santos, M. (November 05, 2013) Evolving insurance industry plays important role in country's growth. Inquirer.net., https://business.inquirer.net/149925/evolvinginsurance-industry-plays-important-role-in-countrysgrowth

[5] History of ASKI MBA Insurance Program. ASKI Mutual Benefit Association, Inc. Website., Retrieved on April 20, 2021, from http://askimba.com.ph/AboutUs.aspx

[6] De Vera, B. (February 04, 2021) Insurance industry net income down $9.85 \%$ to $\mathrm{P} 28.62 \mathrm{~B}$ in end-Q3 2020. Inquirer.net.,

https://business.inquirer.net/316986/insurance-industry-netincome-down-9-85-to-p28-62b-in-end-q3-2020

[7] De Vera, B. (April 30, 2021) Insurer profit down 8.6 percent in 2020 as pandemic hammers markets. Inquirer.net., https://business.inquirer.net/322053/insurerprofit-down-8-6-percent-in-2020-as-pandemic-hammersmarkets

[8] Babuna P., et al. (2020) The Impact of Covid19 on the Insurance Industry. National Center for Biotechnology Information Search Database., https://www.ncbi.nlm.nih.gov/pmc/articles/PMC7459729/

[9] Gudiamt A. and Siy J. (2017) Determinants of Profitability in Life Insurance Companies: Evidence from the Philippines. International Research Institute., http://www.irisro.org/economics2017january/52JSSiy.pdf

[10] Etikan L. (2016) Comparison of convenience sampling and purposive sampling. Researchgate.net., https://www.researchgate.net/publication/304339244_Com parison_of_Convenience_Sampling_and_Purposive_Sampl ing

[11] Salangsang, L., \& Subia, G. (2020). Mathematical thinking on problem-solving and self-regulation strategies of Filipino primary grade pupils. International Journal of Scientific \& Technology Research, 9(2). ISSN 2277-8616

[12] Subia, G. S. Treasure Chess: Worthy Contributions of the Game in the Lives of Student Champions. The Normal Lights, (2020), 14(1):100-121.

[13] Mina, J., Subia, G. \&Ermita, P. (2020). Value Chain Analysis of Slipper Industry in the Footwear Capital of the North. International Journal of Supply Chain Management. Vol.9, No.5, 178-183. 